\title{
OKRA FRUIT GUM-CHITOSAN IMPREGNATED POLYMER NETWORK FILMS: FORMULATION AND SUBSTANTIAL DEPICTION
}

\author{
MEENU NAGPAL ${ }^{1}$, GEETA AGGARWAL ${ }^{2 *}$, UPENDREA K JAIN ${ }^{1}$, JITENDER MADAN ${ }^{1}$ \\ ${ }^{1}$ Department of Pharmaceutics, Chandigarh College of Pharmacy, Mohali - 140 307, Punjab, India. ${ }^{2}$ Department of Pharmaceutics, Delhi
} Pharmaceutical Sciences and Research University, New Delhi - 110 017, India. Email: geetaaggarwal17@gmail.com

Received: 30 May 2017, Revised and Accepted: 27 June 2017

\begin{abstract}
Objective: The present research is aimed at formulation and evaluation of okra fruit gum (OFG)-chitosan (CH) impregnated polymer network films.

Methods: The film forming property of the gum attained from fruits of Abelmoschus esculentus was enhanced by co-processing it with CH. Estimation of properties including swelling index (SI), film volume, volume index, film surface contact angle with buffer solutions (pH 1.2, 7.4 or 6.8), work of adhesion (Wa), and spreading coefficient was done.
\end{abstract}

Results: The contact angle and SI of OFG-CH film in both acidic and alkaline buffers were witnessed to be lowest when equated with the films prepared with difference in ratios of both gum and $\mathrm{CH}$. Moreover, the Wa and spreading coefficient were less for this film. These results could be attributed to the optimum interaction between $-\mathrm{COO}^{-}$groups of gum and $-\mathrm{NH}^{+}$groups of $\mathrm{CH}$.

Conclusion: The actual nature of the film found to be tough, flexible, and water resistant. Hence, the results have shown that the films produced have a high potential for use in modified drug release and in food and pharmaceuticals.

Keywords: Chitosan, Contact angle, Okra, Film, Spreading coefficient, Work of adhesion.

(C) 2017 The Authors. Published by Innovare Academic Sciences Pvt Ltd. This is an open access article under the CC BY license (http://creativecommons. org/licenses/by/4. 0/) DOI: http://dx.doi.org/10.22159/ajpcr.2017.v10i10.20362

\section{INTRODUCTION}

The researchers are now focusing on the exploration of the components from green materials for becoming progressively endorsed alternative for cuisine industry and medicine. Using renewable resources condensed the obligation for nonrenewable resources as implication in packaging and other single use solicitations. Natural materials possess a merit of being profusely available, biodegradable and biocompatible and have shown good forbearance due to their non-toxic nature as compared to synthetic material. Furthermore, the chemical structure of these natural products proposed that the varied functional groups employed could be reacted/cross-linked with other ions/polymers for layout of new materials for unambiguous applications.

The fruit of Bhindi (in Hindi language) plant (Abelmoschus esculentus; Malvaceae family) is found copiously in many areas around the world. The mucilage of Bhindi has been used for treating various diseases such as diarrhea, dysentery, and gastric ulcer as calming softener. Alqasoumi [1] and Gürbüz et al. [2] testified that extract of okra in methanol possessed a gastroprotective effect in rats suffering from gastric ulcer induced with ethanol. Okra mucilage, when mixed with ripe banana, possess its application in the treatment of various GIT diseases including colitis, cystitis, hepatitis, and jaundice [1]. The gum has adequate film forming property which will further anguish its utilization in constitution of foodstuff and application in delivery of various drugs. The okra fruit gum (OFG) is acidic in nature, and the structure constitutes of galactose, rhamnose, and galacturonic/ glucuronic acid [3]. This announces the pertinence of free $-\mathrm{COO}^{-}$ moieties. Thus, co-processing of okra with a polymer possessing excellent film farming property could lead to augmentation of the employment of okra in food and medicine. Chitosan $(\mathrm{CH})$ is reported to possess films of valuable strength owing to its properties such as being safe, polycationic, bioadaptable, and ecological in nature $[4,5]$. $\mathrm{CH}$ has been considered as useful for regulating the release of drugs from their dosage forms. Contrary to this, the property of $\mathrm{CH}$ being soluble in stomach acidic $\mathrm{pH}$, efforts are put on derivatization or cross-linking it for amending drug release peculiarity $[6,7]$. The researchers have worked to enhance the film forming property of various polysaccharides such as chondroitin [8], sodium citrate [9], sodium alginate [10], and co-processing with $\mathrm{CH}$. The drug delivery in colorectal drug release dosage forms [11], sustained release drug delivery systems [12] and transdermal film formulations [7], has been improved through these films.

The interactions of $-\mathrm{COO}^{-}$functional groups of polysaccharides with the $-\mathrm{NH}^{+}$groups of ionized $\mathrm{CH}$ molecule could result in the alteration of film forming capability and drug release regulation property [11]. Based on the phenomena, -COO groups present in galacturonic acid of OFG could be interacted with $-\mathrm{NH}^{+}$groups present in $\mathrm{CH}$ molecules. This interaction can be conjectured to improvise the utilitarian properties of putative $\mathrm{OFG}$ and $\mathrm{CH}$.

This article emphasize on the preparation of films using a combination of OFG and $\mathrm{CH}$. In addition, the evaluation of films was done for reconnoitering their potential in food and pharmaceutical industry.

\section{MATERIALS AND METHODS}

Materials

The purchase of Okra fruit was done from the local market of Chandigarh. $\mathrm{CH}$ was purchased from Merck Pharmaceuticals and Pvt. Ltd. (Ahmedabad, India). The supplier of ammonium acetate and acetic acid was Loba Chemie, India. All chemicals used in the research were of high analytical grade and were used without modification.

\section{Extraction of OFG}

The method used for extraction of the gum was amended as given by Nagpal et al. [13]. In brief, a slurry of cleaned, sliced fruits were prepared by mixing in $3 \% \mathrm{v} / \mathrm{v}$ glacial acetic acid solution, and gum was extracted in $1000 \mathrm{ml}$ beaker by addition of appropriate amount of distilled water 
for $2 \mathrm{hrs}$ at $65^{\circ} \mathrm{C}$. Afterward, the filtration of slurry was performed using a muslin cloth to remove debris. The precipitation of gum was made by the inclusion of abundant acetone. The master of precipitates was removed in a vacuum oven at $60^{\circ} \mathrm{C}$, and $\mathrm{OFG}$ sample was purified by dialysis. Further, lyophilization was performed to obtain a greenish powder. OFG powder obtained was put in the balance for weighing and yield was calculated.

\section{Preparation of CH-OFG conjoin}

A CH-OFG (1:1) conjoin was prepared by the method mentioned below. In brief, $\mathrm{CH}$ solution (prepared by adding $3 \% \mathrm{v} / \mathrm{v}$ acetic acid) was mixed with the solution of OFG in water dropwise, using homogenizer, to obtain gelatin like precipitates. The gelatinous precipitates obtained were dried in oven at $60^{\circ} \mathrm{C}$ for $48 \mathrm{hrs}$ and then microwaved $(80 \mathrm{~W}$, 10 seconds, 15 cycles) to remove any bound water.

\section{Preparation of solution of $\mathrm{CH}-\mathrm{OFG}$ for production of films}

In this, an attempt was made to prepare films of $\mathrm{CH}-\mathrm{OFG}$ in varied ratios, i.e., 10:90, 20:80, 30:70, 40:60, 50:50, 60:40, 70:30, 80:20, and $90: 10$. The total weight of the polymer (ammonium acetate) was kept constant at $2 \% \mathrm{w} / \mathrm{v}$. $3 \% \mathrm{v} / \mathrm{v}$ acetic acid was used for solubilizing $\mathrm{CH}$. OFG is soluble in water. Thus, in another beaker, OFG was dissolved discretely in lukewarm water. $4 \mathrm{M}$ ammonium acetate was solubilized in water. The solution of ammonium acetate was then divided into two parts. One part was added to the $\mathrm{CH}$ solution (A) while another part was added to the OFG solution (B). This was followed by dropwise addition of solution A to solution B accompanied by uninterrupted stirring leading to the formation of a transparent solution of $\mathrm{CH}-\mathrm{OFG}$

\section{Preparation of film containing CH-OFG}

The films of CH-OFG were prepared using spray gun (Electrolab, PP20IV, Mumbai, India) of $1 \mathrm{~mm}$ nozzle. The transparent solution prepared above was sprinkled on a smooth emollient surface of rotating drum. Warm air at $55^{\circ} \mathrm{C}$ is puffed to remove the solvent present in the film. The restrained water present was dislodged using the microwave at $80 \mathrm{~W}$, 20 seconds, 4 cycles. The prepared films were stocked for future usage.

\section{Substantial depiction of CH-OFG films}

Depiction of contact angle of varied buffer solutions ( $p H$ 1.2, 7.4 or 6.8) with film surface

The procedure reported by Jindal et al. [4] was altered for attaining the angle of contact of different buffers with the surface of films engaging different ratios of $\mathrm{CH}$ :OFG. Picture was taken using a digital camera (CANON, 20 Megapixel, 20× zoom, in Mega mode) was used for this purpose. A micropipette $(200 \mathrm{ml})$ was used to put a bead of each buffer solution softly over the surface of the film. The photographs grabbed were exaggerated and were produced on A4 paper. Manual calculation was done for the calculating the contact angle of the drop. The mean of 12 readings is reported in results.

\section{Volume of films}

For the computation of the volume of films $\left(\mathrm{V}_{\mathrm{f}}\right)$, films were allowed to swell. The weight of the swollen film in air $\left(\mathrm{W}_{\mathrm{air}}\right)$ and in $\mathrm{n}$-heptane $\left(\mathrm{W}_{\text {heptane }}\right)$ was determined, heptane being a nonsolvent for the CH-OFG films. $V_{f}$ was figured with the help of buoyancy principle:

$$
\mathrm{V}_{\mathrm{f}}=\frac{\text { Wait }- \text { Wheptane }}{\rho_{\text {heptane }}}
$$

Where, $\rho_{\text {heptane }}$ is the density $\left(0.684 \mathrm{~g} / \mathrm{cm}^{2}\right)$ of n-heptane.

\section{Volume index $\left(V_{i}\right)$}

For attaining the volume index of the films $\left(\mathrm{V}_{\mathrm{f}}\right)$, film volume was assured in air $\left(\mathrm{V}_{\text {air }}\right)$ and in n-heptane $\left(\mathrm{V}_{\mathrm{h}}\right)$ and calculated using the buoyancy principle:

$$
\mathrm{V}_{\mathrm{i}}=\frac{\mathrm{V}_{\text {air }}-\mathrm{V}_{\text {heptane }}}{\mathrm{V}_{\text {hep tane }}}
$$

\section{Work of adhesion (Wa)}

The contact angle was employed to calculate the Wa using the equation:

$\mathrm{Wa}=\gamma \mathrm{L}(\cos \theta+1)$

Where, $\gamma \mathrm{L}$ is the surface tension of the respective buffer calculated using stalagmometer method.

\section{Spreading coefficient}

Spreading coefficient at the buffer film surface was calculated using the equation:

$S=\gamma L(\cos \theta-1)$

Where, $\gamma \mathrm{L}$ is the surface tension of the respective buffer calculated using stalagmometer method.

\section{RESULTS}

One of the major excuses for a restricted application of presumed forms of OFG and $\mathrm{CH}$ in the industry is due to their moderate film forming ability. $\mathrm{CH}$ is a natural polymer but has low or no solubility in aqueous solution but is conveniently soluble in dilute acids and possess favorable film forming properties [8]. $-\mathrm{NH}_{-}^{+}$groups are existent in $\mathrm{CH}$ molecule in an ionized form while, $-\mathrm{COO}^{-}$groups are present in OFG. Thus, it is envisioned that the interaction of these groups can succumb a material with enhanced physicochemical, performance.

\section{Preparation of CH-OFG films}

The preparation of $\mathrm{CH}-\mathrm{OFG}$ conjugate by addition of $\mathrm{CH}$ dissolved in a solution of acetic acid solution to solution of OFG BFG solution resulted in the formation of white gelatinous precipitates which do not have capability of forming films. This might be on account of instinctive reaction of $\mathrm{CH}$ with OFG. Acetic acid dissolved $\mathrm{CH}$ abide $-\mathrm{NH}_{3}{ }^{+}$group. OFG accommodate galacturonic acid that contains $-\mathrm{COO}^{-}$group. Thus, it can be justified that the formation of insoluble white gelatinous precipitates is due to the reaction between $-\mathrm{NH}_{3}{ }^{+}$group of $\mathrm{CH}$ and $-\mathrm{COO}^{-}$ group of OFG. Thus, there was need of addition of ammonium acetate to control this ionic interaction between $\mathrm{CH}$ acetate and solution of OFG. The mixture of $\mathrm{CH}$ acetate solution and OFG solution, resulting in the formation of the clear solution, was sprayed over surface of glass and dried at $50^{\circ} \mathrm{C}$. During the process of drying, there was slow evaporation of ammonium acetate and excess acetic acid resulting in the formation of unwrinkled, ductile and brown colored film. Films could not be formed using OFG alone. Furthermore, the films formed using $\mathrm{CH}$ alone were very tough and breakable. That is why batches containing 10:90, 20:80, 80:20, and 90:10 were rejected. Supplementary, satisfactory films were procured using CH: OFG in the ratio of 30:70, 40:60, 50:50, 60:40, and 70:30, which were further evaluated for physico-chemical peculiarity.

\section{Substantial performance of CH-OFG films}

Swelling index (SI)

SI announces the magnitude of water subdued innards the film [14,15]. Table 1 and Fig. 1 indicates SI of different batches of films in varied buffer pH1.2, 7.4, and 6.8. It was found that OC3 film has the lowest SI, which further differs $(\mathrm{p}<0.05)$ for films in all buffers except for F4 film in buffer of $\mathrm{pH}$ 1.2. This indicates the water resistant nature of the film.

\section{Film volume $\left(V_{p}\right)$}

A variation in diametric and/or thickness of films on coming in contact with buffer $\mathrm{pH} 1.2,7.4$ or 6.8 is indicated by $\mathrm{V}_{f}$ As shown in Table 1 and Fig. 1, OC3 film has lowest $V_{f}$ value as compared to other films. This pinpoint the minimum changes in the measurement of the film, which could be result of formation of high crosslinking between OFG: $\mathrm{CH}$.

$V i$

$\mathrm{V}_{\mathrm{i}}$ signifies corresponding transformation in specification of the volume of film with reference to the dried film. It was observed that value of 
Table 1: Physical properties of different films containing CH-OFG

\begin{tabular}{|c|c|c|c|c|c|c|c|c|c|c|c|}
\hline \multirow[t]{2}{*}{ S. No. } & \multirow[t]{2}{*}{ Film code } & \multicolumn{2}{|c|}{ Composition } & \multirow[t]{2}{*}{ Buffer } & \multirow[t]{2}{*}{ SI } & \multirow[t]{2}{*}{$\mathbf{V}_{\mathrm{f}}$} & \multirow[t]{2}{*}{$\mathbf{V}_{\mathrm{i}}$} & \multirow[t]{2}{*}{$\boldsymbol{\theta}$} & \multirow[t]{2}{*}{$\cos \theta$} & \multirow[t]{2}{*}{ Wa } & \multirow[t]{2}{*}{ S.C } \\
\hline & & $\mathbf{C H}$ & OFG & & & & & & & & \\
\hline \multirow[t]{3}{*}{1} & OC1 & 30 & 70 & pH 1.2 & $5.6 \pm 0.12$ & $66.60 \pm 1.23$ & $16.41 \pm 1.12$ & $40.7 \pm 1.12$ & -0.99 & $0.69 \pm 0.04$ & -139.54 \\
\hline & & & & pH 7.4 & $4.9 \pm 0.15$ & $75.82 \pm 2.12$ & $20.32 \pm 0.09$ & $59.8 \pm 1.31$ & -0.99 & $0.42 \pm 0.03$ & -141.97 \\
\hline & & & & pH 6.8 & $4.4 \pm 0.16$ & $25.10 \pm 1.45$ & $8.25 \pm 1.14$ & $63.3 \pm 2.15$ & 0.89 & $136.63 \pm 0.03$ & -7.77 \\
\hline \multirow[t]{3}{*}{2} & OC2 & 40 & 60 & pH 1.2 & $4.5 \pm 0.05$ & $31.24 \pm 2.12$ & $9.19 \pm 0.97$ & $44.3 \pm 1.25$ & 0.95 & $136.73 \pm 0.04$ & -3.51 \\
\hline & & & & pH 7.4 & $3.9 \pm 0.07$ & $88.92 \pm 1.45$ & $23.51 \pm 2.12$ & $67.1 \pm 2.12$ & -0.43 & $40.60 \pm 0.05$ & -101.80 \\
\hline & & & & pH 6.8 & $4.2 \pm 0.06$ & $16.72 \pm 2.41$ & $6.12 \pm 0.74$ & $74.3 \pm 2.31$ & 0.46 & $105.06 \pm 0.07$ & -39.34 \\
\hline \multirow[t]{3}{*}{3} & OC3 & 50 & 50 & pH 1.2 & $4.2 \pm 0.06$ & $16.71 \pm 2.45$ & $5.12 \pm 0.76$ & $79.3 \pm 2.45$ & -0.72 & $19.31 \pm 0.17$ & -120.94 \\
\hline & & & & pH 7.4 & $2.5 \pm 0.08$ & $8.97 \pm 1.74$ & $3.57 \pm 0.59$ & $87.6 \pm 1.92$ & 0.93 & $137.71 \pm 1.14$ & $-4.6 \mathrm{~B}$ \\
\hline & & & & pH 6.8 & $3.2 \pm 0.14$ & $11.25 \pm 1.12$ & $4.09 \pm 0.71$ & $65.7 \pm 1.11$ & -0.64 & $26.03 \pm 0.98$ & -118.37 \\
\hline \multirow[t]{3}{*}{4} & OC4 & 60 & 40 & pH 1.2 & $4.8 \pm 0.08$ & $40.99 \pm 1.23$ & $11.26 \pm 0.74$ & $49.2 \pm 2.23$ & 0.48 & $105.66 \pm 1.25$ & -36.18 \\
\hline & & & & $\mathrm{pH} 7.4$ & $3.7 \pm 0.09$ & $8.97 \pm 1.47$ & $6.12 \pm 0.84$ & $82.4 \pm 2.25$ & 0.75 & $124.79 \pm 1.92$ & -17.61 \\
\hline & & & & pH 6.8 & $4.7 \pm 0.13$ & $11.25 \pm 1.71$ & $11.12 \pm 0.71$ & $82.9 \pm 2.12$ & 0.34 & $97.11 \pm 1.17$ & -47.29 \\
\hline \multirow[t]{3}{*}{5} & OC5 & 70 & 30 & pH 1.2 & $5.4 \pm 0.07$ & $16.29 \pm 1.41$ & $16.31 \pm 1.12$ & $44.2 \pm 2.15$ & 0.98 & $138.74 \pm 1.58$ & -1.66 \\
\hline & & & & pH 7.4 & $4.7 \pm 0.14$ & $12.20 \pm 1.71$ & $14.18 \pm 1.09$ & $63.5 \pm 2.91$ & 0.78 & $127.08 \pm 1.47$ & -15.31 \\
\hline & & & & pH 6.8 & $4.9 \pm 0.11$ & $13.31 \pm 0.98$ & $13.28 \pm 0.91$ & $79.8 \pm 1.85$ & -0.31 & $50.13 \pm 1.74$ & -94.27 \\
\hline
\end{tabular}

OFG: Okra fruit gum, CH: Chitosan, SI: Swelling index, $\mathrm{V}_{\mathrm{f}}$ : Film volume, $\mathrm{V}_{\mathrm{i}}$ : Volume index, Wa: Work of adhesion

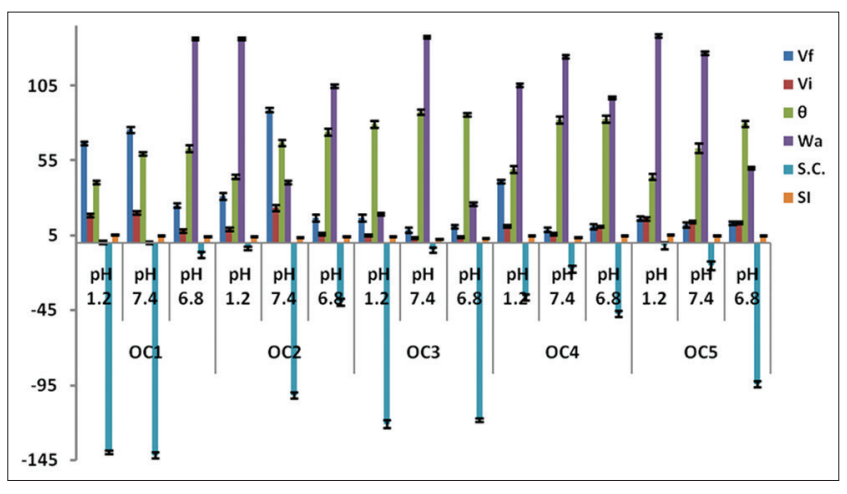

Fig. 1: Physical properties of different films containing chitosanokra fruit gum

Vi of OC3 film was found to be lowest and significantly different from volume index of other films in all other buffers. The lowest values of $\mathrm{SI}, \mathrm{Vf}$, and Vi of OC3 formulation proved maximum interaction between 50:50 proportion of $\mathrm{CH}$ and OFG that might would have been a result of the appropriate interpenetrating network with a good amount of cross linking density (Table 1 and Fig. 1).

\section{Film surface contact angle}

The contact angle with film surface at different buffers ( $\mathrm{pH} 1.2,7.4$ or 6.8) is envisioned to indicate the relative hydrophilic/lipophilic nature of the film. Moreover, an increase in contact angle increases the lipophilicity of the film surface. The contact angle of the OC3 formulation was found to be maximum in all the buffers as compared to all other formulation indicating lipophilic character of the film (Table 1 and Fig. 1).

\section{Wa}

Wa signifies bonding between the buffer and film surface. The results of Wa are shown in Table 1 and Fig. 1.

\section{Spreading coefficient}

All the film surfaces have negative spreading coefficient (Table 1 and Fig. 1).

\section{DISCUSSION}

From the results mentioned above, OC3 film formulation was found to be better than other films. It could be due to the most favorable interaction between $-\mathrm{COO}^{-}$groups of $\mathrm{OFG}$ and $-\mathrm{NH}^{+}$groups of $\mathrm{CH}$ during film formation resulting in slightest possibility of functional groups of $\mathrm{CH}$ and $\mathrm{OFG}$ for hydrogen bonding with water. The contact angle of OC3 film was found to be maximum in buffer $\mathrm{pH} 7.4$, followed by $\mathrm{pH} 6.8$ and minimum in $\mathrm{pH} 1.2$. It might be explained as from formulation $\mathrm{OC} 1$ to $\mathrm{OC} 5$, the percentage of $\mathrm{CH}$ increased where as that of OFG decreased. It can be considered in OC1 and OC2 films, the percentage of OFG would have been in excess of $\mathrm{CH}$ whereas, in OC4 and in OC5 formulations, the content of $\mathrm{CH}$ would have been in excess of OFG. OFG would be in unionized form in acidic $\mathrm{pH}$, while $\mathrm{CH}$ would be unionized in alkaline $\mathrm{pH}$. The data presented in Table 1 indicate that the contact angle of all other buffers increased for OC1 to OC3 films and then decreased for OC4 and OC5 films. The pattern recognized for contact angle for all the buffer solutions is defensible on the footing of the content of $\mathrm{CH}$ and BFG present in various films in ionized form. Wa is signifies the effort needed to isolate the buffer from the exterior of film. The surface of OC3 film was more troublesome to wet when correlated to the surface of other films illustrated lowest work adhesion irrespective of the $\mathrm{pH}$ of the buffer. In addition, the Wa values of OC3 film was found to be significantly $(p<0.05)$ different with respect to those of other films in all the buffers (Table 1). Negative value of spreading coefficient results in the formation of globule rather than film of liquid over a film surface [16]. Thus, the spreading coefficient signified comparatively less water-loving character of all the film surfaces. However, the spreading coefficient for OC3 film was found to be minimum for all the buffer. Hence, it could be proposed that the OC3 film formed by the maximal interaction of $\mathrm{CH}$ and $\mathrm{OFG}$ was least wettable as compared to other film surfaces that probably contained few unreacted functional groups of $\mathrm{CH}$ or OFG. Those unreacted functional groups of $\mathrm{CH}$ and OFG could have been available for interaction with water molecules, thus yielding relatively hydrophilic surface as compared to the OC3 film.

\section{CONCLUSION}

It is, thus, concluded that $-\mathrm{COO}^{-}$moieties present in $\mathrm{OFG}$ and $-\mathrm{NH}^{+}$ moieties present in $\mathrm{CH}$ interacted to form $\mathrm{CH}-\mathrm{OFG}$ film. The values of SI and contact angle measurements suggested that OC5 film containing an equal proportion of $\mathrm{CH}$ and $\mathrm{OFG}$ in the ratio of 50:50 showed more lipophilic character in comparison to other films. This might due to nonavailability of free functional groups in OC3 formulation to interact with water. The same justification manifested in lowest work of adhesion and spreading coefficient of OC3 formulation.

Thoroughly, in the above research, it was indicated that OC3 films containing 50:50 $\mathrm{CH}$ and OFG proved to play an auspicious role for modification of drug release, water permeability, protection of moisture sensitive edible items, etc. Furthermore, both CH and OFG are admitted to be safe for oral consumption. Hence, these films could be oppressed for use in food items. 


\section{ACKNOWLEDGMENT}

The authors are thankful to I.K. Gujral Punjab Technical University, Punjab, India, for supporting the research project.

\section{REFERENCES}

1. Alqasoumi SI. 'Okra' Hibiscus esculentus L.: A study of its hepatoprotective activity. Saudi Pharm J 2012;20(2):135-41.

2. Gürbüz I, Ustün O, Yesilada E, Sezik E, Kutsal O. Anti-ulcerogenic activity of some plants used as folk remedy in Turkey. J Ethnopharmacol 2003;88(1):93-7.

3. Kaur G, Singh D, Brar V. Bioadhesive okra polymer based buccal patches as platform for controlled drug delivery. Int J Biol Macromol 2014;70:408-19.

4. Jindal M, Kumar V, Rana V, Tiwary AK. Physico-chemical, mechanical and electrical performance of bael fruit gum-chitosan IPN films. Food Hydrocoll 2013;30(1):192-9.

5. Rao MS, Kanatt SR, Chawla S, Sharma A. Chitosan and guar gum composite films: Preparation, physical, mechanical and antimicrobial properties. Carbohydr Polym 2010;82(4):1243-7.

6. Risbud MV, Hardikar AA, Bhat SV, Bhonde RR. pH-sensitive freezedried chitosan-polyvinyl pyrrolidone hydrogels as controlled release system for antibiotic delivery. J Control Release 2000;68(1):23-30.

7. Sivakumar M, Manjubala I, Panduranga RK. Preparation, characterization and in vitro release of gentamicin from coralline hydroxyapatite-chitosan composite microspheres. Carbohydr Polym 2002;49(3):281-8.

8. Bhise KS, Dhumal RS, Chauhan B, Paradkar A, Kadam SS. Effect of oppositely charged polymer and dissolution medium on swelling, erosion, and drug release from chitosan matrices. AAPS PharmSciTech
2007;8(2):Article 44

9. Chen HS, Moschakis T, Nelson P. Application of surface friction measurements for surface characterization of heat-set whey protein gels. J Texture Stud 2004;35:493-510.

10. Arzate-Vázquez I, Chanona-Pérez JJ, Calderón-Domínguez G, TerresRojas E, Garibay-Febles V, Martínez-Rivas A, et al. Microstructural characterization of chitosan and alginate films by microscopy techniques and texture image analysis. Carbohydr Polym 2012;87(1):289-99.

11. Naidu VG, Madhusudhana K, Sashidhar RB, Ramakrishna S, Khar RK, Ahmed FJ, et al. Polyelectrolyte complexes of gum kondagogu and chitosan, as diclofenac carriers. Carbohydr Polym 2009;76:464-71.

12. Kumar MN, Muzzarelli RA, Muzzarelli C, Sashiwa H, Domb AJ. Chitosan chemistry and pharmaceutical perspectives. Chem Rev 2004;104(12):6017-84

13. Nagpal M, Aggarwal G, Jain UK, Madan J. Extraction of gum from Abelmoschus esculentus: Physicochemical peculiarity and antioxidant prepatent. Asian J Pharm Clin Res. Available from: https://www. innovareacademics.in/journals/index.php/ajpcr/issue/archive.

14. Nehete J, Bhatia M. Correlation of antioxidant activity with phenolic content and isolation of antioxidant compound from Lygodium flexuosum (L.) SW extracts. Int J Pharm Pharm Sci 2011;3:48-52.

15. Meera G, Leenamma J, Josekumar VS. Antioxidant, anti-lipid peroxidative and antimicrobial properties of the epiphytic fern, Pyrrosia heterophylla (L.) Int J Pharm Pharm Sci 2017;9(4):87-93.

16. Singh K, Suri R, Tiwary AK, Rana V. Chitosan films: Crosslinking with EDTA modifies physicochemical and mechanical properties. J Mater Sci Mater Med 2012;23(3):687-95. 